\title{
Heat Transfer of Aviation Kerosene at Supercritical Conditions
}

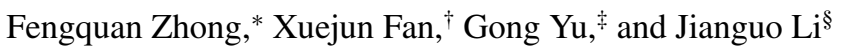 \\ Chinese Academy of Sciences, 100190 Beijing, People's Republic of China \\ and \\ Chih-Jen SungI \\ Case Western Reserve University, Cleveland, Ohio 44106
}

\section{DOI: $\underline{10.2514 / 1.41619}$}

\begin{abstract}
The heat transfer characteristics of China no. 3 kerosene were investigated experimentally and analytically under conditions relevant to a regenerative cooling system for scramjet applications. A test facility developed for the present study can handle kerosene in a temperature range of 300-1000 K, a pressure range of 2.6-5 MPa, and a mass flow rate range of 10-100 g/s. In addition, the test section was uniquely designed such that both the wall temperature and the bulk fuel temperature were measured at the same location along the flowpath. The measured temperature distributions were then used to analytically deduce the local heat transfer characteristics. A 10-component kerosene surrogate was proposed and employed to calculate the fuel thermodynamic and transport properties that were required in the heat transfer analysis. Results revealed drastic changes in the fuel flow properties and heat transfer characteristics when kerosene approached its critical state. Convective heat transfer enhancement was also found as kerosene became supercritical. The heat transfer correlation in the relatively low-fuel-temperature region yielded a similar result to other commonly used jet fuels, such as JP-7 and JP-8, at compressed liquid states. In the high-fuel-temperature region, near and beyond the critical temperature, heat transfer enhancement was observed; hence, the associated correlation showed a more significant Reynolds number dependency.
\end{abstract}

\section{Introduction}

$\mathbf{T}$ HERMAL management is a key element for successful scramjet applications. Regenerative fuel cooling has been considered one of the most effective and practical methods for hydrocarbonfueled scramjets [1-ㅗㄱ. In a regenerative cooling system, before injection into combustor, the fuel flows through the cooling channels along the combustor wall, carrying away heat from the wall via heat convection and endothermic chemical reactions (thermal cracking) $[4,5]$. A challenge for regenerative cooling systems is that the amount of the fuel used as coolant must match that used for the combustion. Hence, with a limited range of fuel mass flow rates, the enhancement of cooling efficiency plays an important role. A fundamental understanding of heat transfer characteristics of fuel flow at various conditions can provide insight into the design and optimization of a regenerative cooling system.

The typical pressure in the cooling channel for scramjet applications is approximately 3-7 MPa, higher than the critical pressure $\left(P_{c} \sim 2 \mathrm{MPa}\right)$ for most hydrocarbon fuels. At the same time, as fuel absorbs heat from the wall, its temperature rises and may exceed the critical temperature $\left(T_{c} \sim 600 \mathrm{~K}\right)$, leading to supercritical fuel. The thermophysical properties of fuel at supercritical states are significantly different from those at compressed liquid

Presented as Paper 4615 at the 44th AIAA/ASME/SAE/ASEE Joint Propulsion Conference \& Exhibit, Connecticut Convention Center Hartford, CT; received 15 October 2008; revision received 24 December 2008; accepted for publication 27 December 2008. Copyright (C) 2009 by the American Institute of Aeronautics and Astronautics, Inc. All rights reserved. Copies of this paper may be made for personal or internal use, on condition that the copier pay the $\$ 10.00$ per-copy fee to the Copyright Clearance Center, Inc., 222 Rosewood Drive, Danvers, MA 01923; include the code 0887-8722/ $09 \$ 10.00$ in correspondence with the CCC.

*Associate Professor, Key Laboratory of High Temperature Gas Dynamics, Institute of Mechanics.

${ }^{\dagger}$ Professor, Key Laboratory of High Temperature Gas Dynamics, Institute of Mechanics; xfan@imech.ac.cn.

FProfessor, Key Laboratory of High Temperature Gas Dynamics, Institute of Mechanics.

§Professor, Key Laboratory of High Temperature Gas Dynamics, Institute of Mechanics.

'Professor, Department of Mechanical and Aerospace Engineering. states and present some unique features. It is known [6,7] that supercritical fuel exhibits a liquidlike density and a gaslike diffusivity. In addition, the variations of many of the fuel thermodynamic and transport properties, such as density, specific heats, viscosity, and thermal conductivity, with temperature are complex, depending on the thermophysical conditions [요, $\underline{\text { ] }}$. Taking China no. 3 kerosene at supercritical pressure as an example, its viscosity is decreased by more than 2 orders of magnitude when the temperature increases from 300 to $800 \mathrm{~K}$ and the change in its specific heat shows a peak at a temperature near the critical point. As such, the empirical formula for the convective heat transfer of liquid and gas, such as the Sieder-Tate correlation [10], will not be valid. It is therefore imperative to study the heat transfer characteristics of hydrocarbon fuels under supercritical conditions relevant to those for scramjet applications.

Among the computational studies on supercritical heat transfer are a computational fluid dynamics analysis using hydrogen [11] and a numerical modeling using water [12]. Most of the previous studies investigating the heat transfer of hydrocarbons were pertinent to rocket cooling applications [13-17], which have quite different flow conditions from scramjet applications. Specifically, for a rocket regenerative cooling system, the average wall heat flux is typically $\geq 500 \mathrm{~W} / \mathrm{cm}^{2}$ due to the small cross-sectional area near the throat of the rocket nozzle, which is approximately 1 order of magnitude larger than that for a Mach 6 scramjet application [18]. The working fuel pressure for a rocket application $(\geq 20 \mathrm{MPa})$ is also considerably higher than that for a scramjet application. Although a rocket application has much higher wall heat flux than a scramjet application, the coolant temperature rise in a rocket cooling system is significantly smaller because of a relatively larger amount of coolant (fuel) and a smaller cooling surface. However, a scramjet cooling system has limited amount of coolant and a much larger cooling surface. Thus, in many studies for rocket applications [13-17], the fuel temperature at the exit of the regenerative cooling system is lower than the fuel critical temperature and the fuel is still in a compressed liquid state, leading to relatively simple heat transfer relations. On the other hand, in a scramjet application, the temperature variation of the hydrocarbon fuel may be from room temperature to its critical temperature and even to a temperature at which significant thermal cracking occurs. Because of the changes in the physical state of the fuel, from a compressed liquid to a 
supercritical state, as well as the possibility of fuel thermal cracking, the associated heat transfer characteristics can vary considerably.

In this paper, the heat transfer characteristics of China no. 3 kerosene at compressed liquid and supercritical states were investigated experimentally and analytically. Experimentally, a two-stage fuel heating system was used to achieve a wide range of fuel preheats, test section temperatures, pressures, and Reynolds numbers for a systematic and parametric investigation. Unlike most of the previous studies, a unique feature of the present work is that within the test section both the wall and fuel temperatures were simultaneously measured at the same location along the fuel flowpath. With the measured temperature profiles, the wall heat flux distribution was deduced analytically. Such an experimental and analytical study over extensive variations in the range of thermodynamic parameters is expected to provide further insight into the kerosene heat transfer characteristics.

In the next section, the test facility and experimental procedure will be introduced. Then, the details of the heat transfer analysis will be discussed, followed by the presentation of experimental results and the associated discussion.

\section{A. Experimental Facility}

\section{Experimental Specifications}

A two-stage heating system, as shown in Fig. 1, was used to obtain the desired flow conditions and, at the same time, to prevent significant carbon formation as a result of the fuel thermal cracking. The first-stage, storage-type heater, which had a volume of approximately 3 liter and a capability of heating $2 \mathrm{~kg}$ of kerosene to a temperature of $500 \mathrm{~K}$ within $1 \mathrm{~h}$, prepared the test fuel to a desired preheat temperature. When the test fuel reached a steady state, it flowed through the second-stage heater, which was heated with heating tapes that had a maximum power of $12 \mathrm{~kW}$. With proper asbestos insulation, the second-stage heater can easily heat kerosene up to $1000 \mathrm{~K}$. A part of this second-stage heater also serves as the test section for investigating the heat transfer characteristics of different flow conditions. The test section was composed of a 21-m-long T304 stainless steel tube with an inner diameter of $12 \mathrm{~mm}$ and a wall thickness of $2 \mathrm{~mm}$. There were transition sections at the inlet and outlet of the test section to ensure a fully developed pipe flow.

The tube pressures at the inlet and outlet of the test section were measured with pressure transducers. There were 16 type-K thermocouples spot-welded on the outer wall surface of the tube for the measurement of the wall temperature along the test section. At approximately the same locations with respect to the 16 wall thermocouples, 16 type-K sheath thermocouples were mounted through the tube wall and positioned at approximately the tube centerline for the measurement of the bulk fuel temperatures. The insets of Fig. 1 illustrate the thermocouple arrangement and assembly. The thermocouples for the bulk fuel temperature measurement had a sheath diameter of $0.5 \mathrm{~mm}$ and a response time of approximately $0.1 \mathrm{~s}$, which is adequate for the current study. To prevent any heat conduction from the tube wall to the thermocouple sheath and to facilitate the mounting process, each fuel thermocouple was covered with a steel tube filled with zirconium dioxide. This thermocouple assembly was then welded on the tube outer wall. The uncertainty associated with the measurements of the wall temperatures and the fuel temperatures was estimated to be less than $\pm 3 \mathrm{~K}$, whereas that of the pressure measurements was less than $1 \%$. All the experimental data were recorded via a data acquisition system for analysis.

A sonic nozzle flow meter was installed downstream of the test section to monitor the fuel mass flow rate. Using the calibration method proposed in our previous studies $[19,20]$, the fuel mass flow rate can be determined for given fuel pressure and fuel temperature upstream of the nozzle, as well as the area of the nozzle throat, because the fuel flow at the nozzle throat is chocked. Sonic nozzles with two throat diameters, 1.6 and $3.08 \mathrm{~mm}$, were used for different mass flow rate ranges. After the sonic nozzle, the heated fuel mixture, kerosene along with products from thermal cracking (if present), can be cooled down to room temperature through a water cooling system and then analyzed using gas/liquid chromatography.

With the current system, the test section can have a maximum wall temperature of approximately $1100 \mathrm{~K}$, a pressure range of 2.6$5 \mathrm{MPa}$, and a fuel mass flow rate range of $10-100 \mathrm{~g} / \mathrm{s}$. In this study, the fuel temperature can vary from 300 to $800 \mathrm{~K}$ as a result of convective heat transfer. Although a further increase in fuel temperature is possible, it was not attempted here because significant thermal cracking was noted [21] to occur at fuel temperatures higher than $800 \mathrm{~K}$. In addition, the Reynolds number of the fuel flow, defined by the tube inner diameter and fuel local properties, ranged from 3000 to 500,000 in the present investigation, whereas the wall heat flux was in the range of $1-30 \mathrm{~W} / \mathrm{cm}^{2}$.

\section{B. Experimental Procedure}

Before each run, $\sim 2 \mathrm{~kg}$ kerosene was prepared to a preset relatively low temperature in the first-stage heater and, at the same time, the test section in the second-stage heater was heated to a specific high temperature. When the setting temperatures in both the first- and second-stage heaters reached steady state, the preheated kerosene in the first-stage heater was then driven by pressurized nitrogen at a given pressure and flowed through the test section, while the heating tapes in the test section were turned off when commencing the heat transfer characterization experiment. It

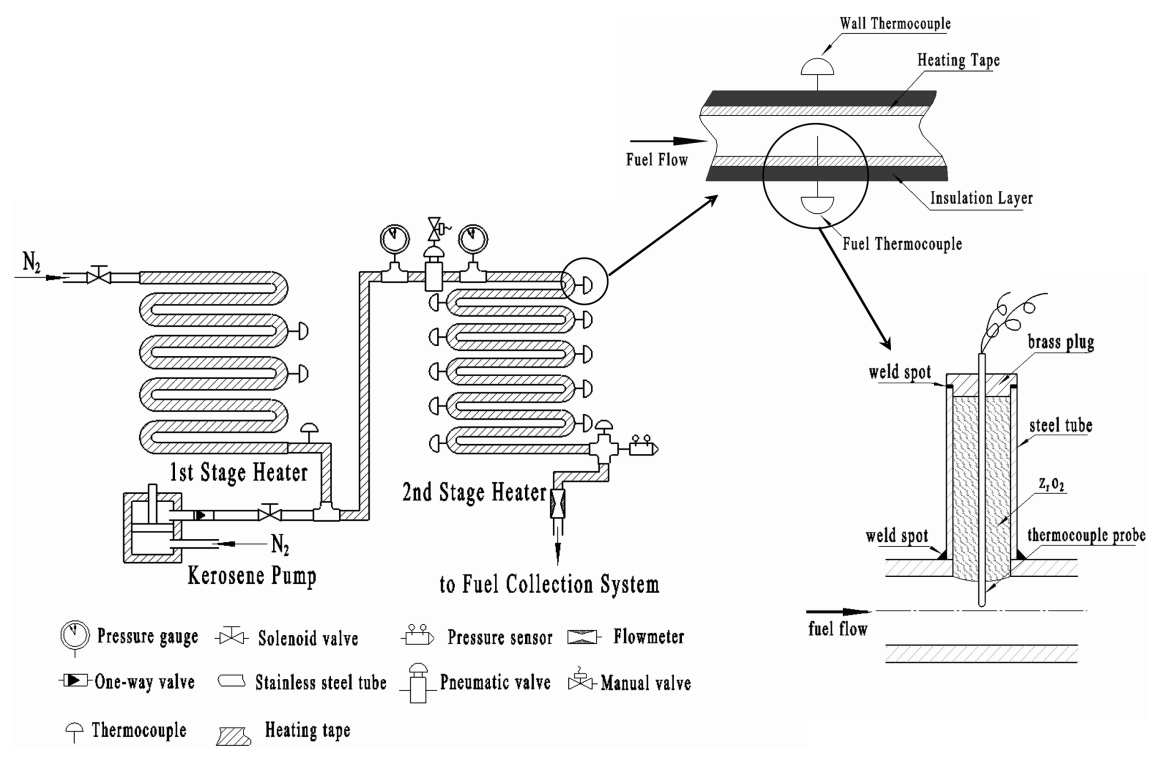

Fig. 1 Schematic diagram of two-stage kerosene heating system, test section, and thermocouple assembly for fuel/wall temperature measurements. 
typically took $6-8 \mathrm{~s}$ for the fuel flow to reach equilibrium. Although the total experiment run time was 13-16 s, in general, the experimental data in the last $4 \mathrm{~s}$ were used for the subsequent heat transfer analysis. After each run, high-pressure air was used to purge out the residual kerosene and carbon deposition (if present) in the test section.

Figure 2 shows the time variations of the pressures at the inlet and outlet of the test section and the fuel temperature measured at the outlet for a mass flow rate of approximately $20 \mathrm{~g} / \mathrm{s}$. It is noted that, at a reference time of $t=1 \mathrm{~s}$, the pneumatic valve downstream of the first-stage heater was opened and the preheated kerosene started to flow into the second-stage heater (test section). To build up the tube pressure within a relatively short time, the second pneumatic valve located downstream of the second-stage heater was still kept closed. At $t=4 \mathrm{~s}$, the second pneumatic valve was opened and the kerosene flowed through the test section. Figure 2 shows that a steady state of the flow at the exit of the test section was established at approximately $t=8 \mathrm{~s}$. It is also seen from Fig. 2 that after $t=8 \mathrm{~s}$ the inlet and outlet pressures were very close, indicating an insignificant pressure drop through the test section.

\section{Analytical Specifications}

\section{A. Heat Transfer Analysis}

The control volume considered is shown in Fig. $\underline{3}$, which is formed by the tube inner wall and two cross sections at adjacent locations along the axial direction separated by $\Delta x$ where the wall and bulk fuel temperatures are measured. Because the kinetic energy of the fuel for the present study is at least 5-6 orders of magnitude smaller than its internal energy, by neglecting the kinetic energy and the viscous effect, the energy equation can be expressed as

$$
\frac{\partial}{\partial t} \int_{V}(\rho e) \mathrm{d} V+\int_{s_{1}+s_{2}+s_{3}}(\rho \mathbf{u} h) \cdot \mathbf{n} \mathrm{d} S=-\int_{s_{1}+s_{2}+s_{3}} \mathbf{q}_{w} \cdot \mathbf{n} \mathrm{d} S
$$

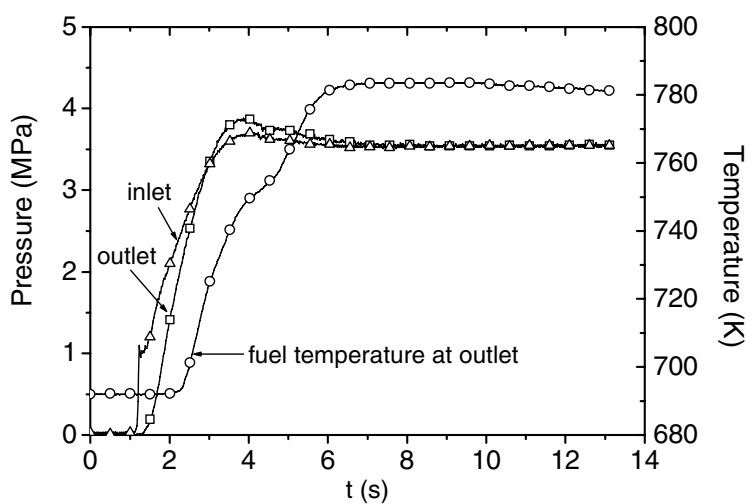

Fig. 2 Time histories of inlet and outlet pressures and outlet fuel temperature of the test section.

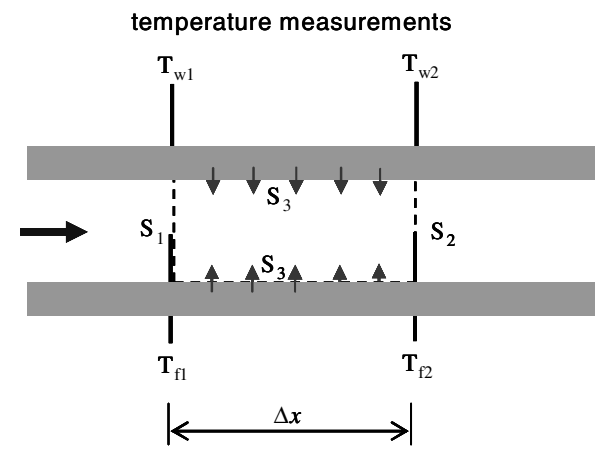

Fig. 3 Control volume for heat transfer analysis. where $S_{1}$ and $S_{2}$ are, respectively, the surfaces on the left and right sides of the control volume, $S_{3}$ is the wall inner surface, $\rho$ is the fuel density, $e$ is the internal energy per unit mass, $h$ is the enthalpy per unit mass, and $\mathbf{q}_{w}$ is the wall heat flux.

Knowing that the axial heat conduction through $S_{1}$ and $S_{2}$ are negligible, Eq. (1) can be simplified as

$$
\frac{\partial(\overline{\rho e})}{\partial t} \Delta V+(\dot{m} h)_{s_{2}}-(\dot{m} h)_{s_{1}}=q_{w} S
$$

where $\overline{\rho e}$ is the average value in the control volume based on the mean fuel temperature $\bar{T}_{f}=\frac{1}{2}\left(T_{f 1}+T_{f 2}\right), \Delta V$ is the volume of the control volume, $\dot{m}$ is the fuel mass flow rate, $q_{w}$ is the mean wall heat flux into the control volume, $S=\pi d \Delta x$ is the surface area of the inner wall, and $d$ is the inner tube diameter.

During the experiment, when the heating tapes were turned off, the wall temperature dropped as the fuel carried away heat. Although the reduction rate of the wall temperature varied with operation conditions and locations, the typical value was approximately several Kelvin per second for the conditions investigated. Hence, the first term in Eq. (2) becomes important and, in turn, plays a significant role in overall heat transfer. For all the cases investigated, the heat flux analysis indicated that the unsteady effect accounted for 10-30\% of the local heat flux.

Considering the mass conservation equation for the control volume,

$$
\frac{\partial \bar{\rho}}{\partial t} \Delta V+\dot{m}_{2}-\dot{m}_{1}=0
$$

the local mass flow rate varies along the tube due to the unsteady effect. Because the mass flow rate at the outlet of the test section can be determined with a sonic nozzle flow meter, the mass flow rate distribution along the tube can be obtained via Eq. (3).

The local heat flux into the control volume is then calculated as follows:

$$
q_{w}=\frac{d}{4} \frac{\partial(\overline{\rho e})}{\partial t}+\frac{\dot{m}_{2} h_{2}-\dot{m}_{1} h_{1}}{\pi d \Delta x}
$$

Here, the first term on the right-hand side indicates the unsteady effect of the fuel flow.

The Nusselt number is expressed as $N u=\lambda d / k$, where $\lambda=$ $q_{w} /\left(\bar{T}_{w}-\bar{T}_{f}\right)$ is the heat transfer coefficient for low-speed flows, $k$ is the fuel thermal conductivity evaluated at the mean fuel temperature $\bar{T}_{f}, \bar{T}_{w}=\frac{1}{2}\left(T_{w 1}+T_{w 2}\right)-q_{w} \ell / k_{w}$ is the inner wall temperature determined based on the assumption of one-dimensional heat conduction through the wall thickness $\ell$, and $k_{w}$ is the thermal conductivity of the stainless tube. Here, $\bar{T}_{w}$ also represents the fuel temperature near the wall. Moreover, the Reynolds number based on the tube inner diameter is defined as $R e=4 \dot{m} /(\pi d \propto)$, where $\propto$ is the fuel viscosity evaluated at $\bar{T}_{f}$.

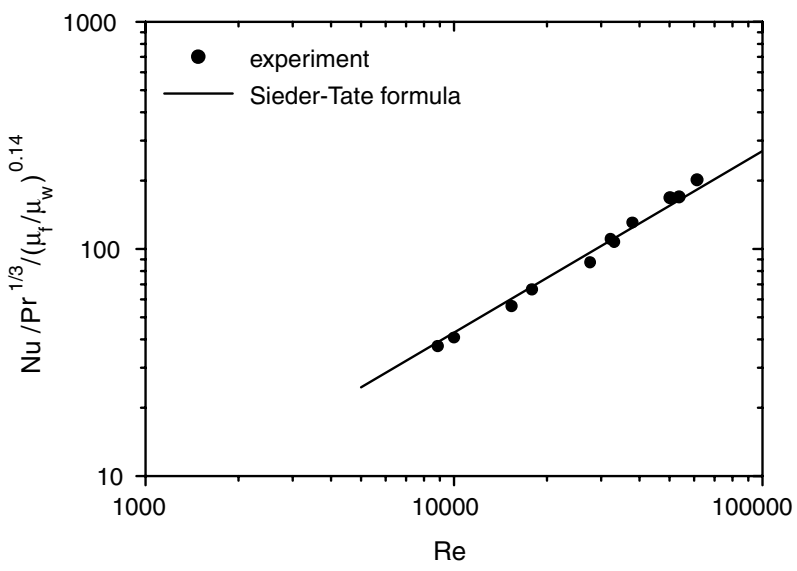

Fig. 4 Heat transfer characterization of nitrogen flows. 
Table 1 Ten-component surrogate of China no. 3 kerosene

\begin{tabular}{lcc}
\hline \hline Composition & & Molar Percentage \\
\hline Alkanes & n-Octane & 6 \\
& n-Decane & 10 \\
& n-Dodecane & 20 \\
& n-Tridecane & 8 \\
& n-Tetradecane & 10 \\
Cycloalkanes & n-Hexadecane & 10 \\
& Methylcyclohexane & 20 \\
\hline Benzenes & trans-1,3-Dimethylcyclopentane & 8 \\
\hline Naphthalenes & Propylbenzene & 5 \\
\hline \hline
\end{tabular}

It is noted that the uncertainty in the deduced heat transfer parameters, such as local wall heat flux $q_{w}$ and heat transfer coefficient $\lambda$, depends on the accuracy of the fuel and wall temperature measurements and the reproducibility of the experimental data. An uncertainty analysis was conducted to determine the uncertainty in the reported values of $q_{w}$ and $\lambda$, yielding $\leq 8 \%$ for $q_{w}$ and $\leq 10 \%$ for $\lambda$.

To demonstrate the adequacy of the temperature measurements and the heat transfer analysis, nitrogen flows at different Reynolds numbers, by varying pressures and mass flow rates, were tested and studied. Figure 4 plots the experimentally determined Nusselt number divided by $\operatorname{Pr}^{1 / 3}\left(\propto_{f} / \propto_{w}\right)^{0.14}$ as a function of Reynolds number, where $\operatorname{Pr}$ is the Prandtl number and $\propto_{f}$ and $\propto_{w}$ are the fuel viscosity values at the bulk fluid temperature and the inner wall temperature, respectively. The Sieder-Tate correlation [10] for turbulent flows, $N u /\left[\operatorname{Pr}^{1 / 3}\left(\propto_{f} / \propto_{w}\right)^{0.14}\right]=0.027 \operatorname{Re}^{0.8}$, is also plotted in Fig. 4 for comparison. A good agreement is shown in Fig. 4, with a discrepancy of less than $\leq 10 \%$.

When analyzing the heat transfer characteristics of kerosene using these equations, the knowledge of various thermodynamic and transport properties of kerosene over a wide range of pressure and temperature variations is required. Recognizing that kerosene contains hundreds to thousands of hydrocarbons, a surrogate fuel model, consisting of a small number of fuel components, can be used to represent the real fuel and predict the desired characteristics of the actual fuel. The development of a kerosene surrogate and the calculations of thermodynamic and transport properties are described in Sec. III.B.

\section{B. Kerosene Surrogate and Evaluation of Thermodynamic and Transport Properties}

A composition analysis showed that China no. 3 kerosene consists of $53 \%$ alkanes, $39 \%$ cycloalkanes, $5 \%$ benzenes, and $3 \%$ naphthalenes by mass. Accordingly, a 10-component surrogate was proposed, as listed in Table 1. The thermodynamic and transport properties as well as the critical point of this surrogate were then calculated with the National Institute of Standards and Technology's SuperTrapp program [22] based on the extended corresponding states model [23]. Compared with the kerosene surrogate proposed in our previous study [20], the current surrogate gives better predictions for fuel properties such as specific heat. The predicted critical temperature and critical pressure of this surrogate are, respectively, $660 \mathrm{~K}$ and 2.4 MPa, whereas the measured critical temperature and critical pressure for China no. 3 kerosene are, respectively, $640 \mathrm{~K}$ and $2.4 \mathrm{MPa}$ [24].

Figures $5 \mathrm{a}$ and $5 \mathrm{~b}$, respectively, show the calculated density and specific heat at constant pressure as a function of temperature with varying pressures. It is seen that, for pressures higher than the critical value, fuel enters the supercritical state directly without going through a two-phase region. Other fuel properties, such as enthalpy, dynamic viscosity, thermal conductivity, etc., were also calculated using SuperTrapp [22] with the 10-component surrogate, based on the assumption that there is no thermal cracking under the conditions investigated. Figures $5 \mathrm{c}$ and $5 \mathrm{~d}$ plot the computed results for dynamic viscosity and thermal conductivity, respectively. A significant

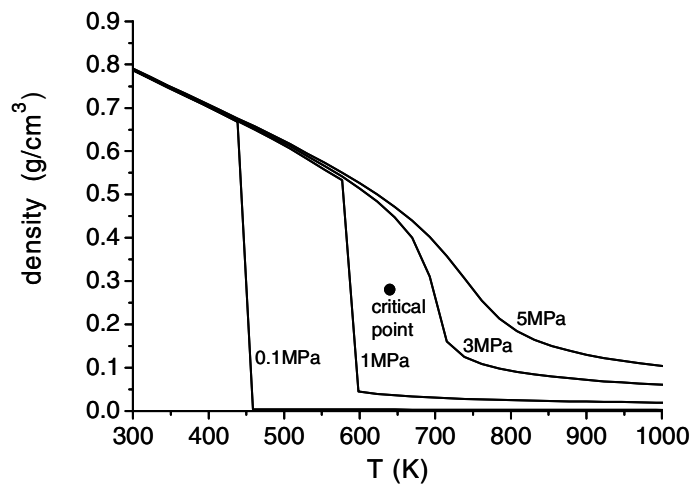

a)

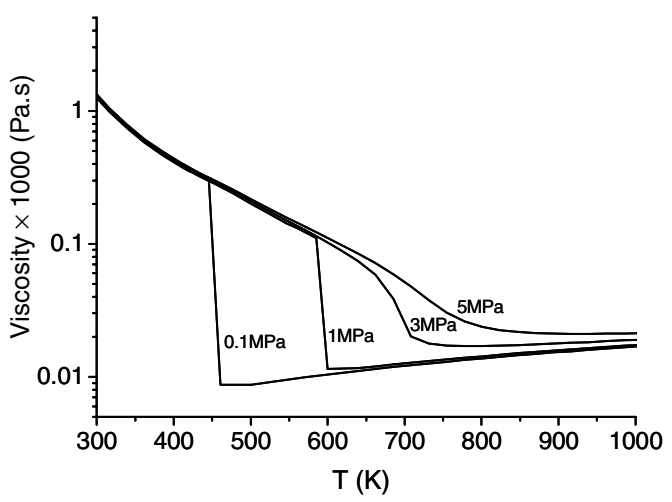

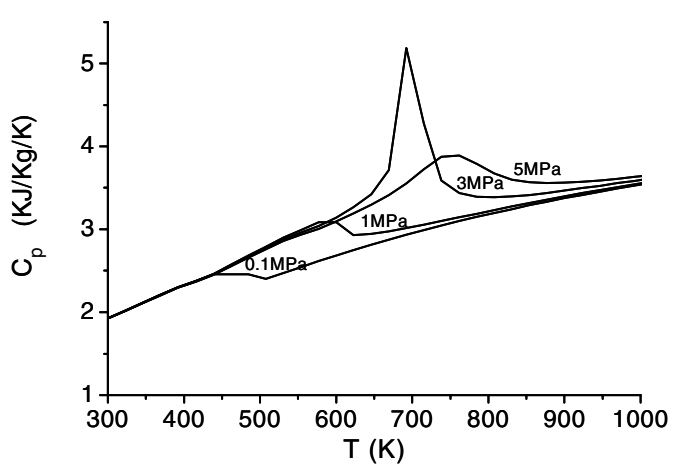

b)

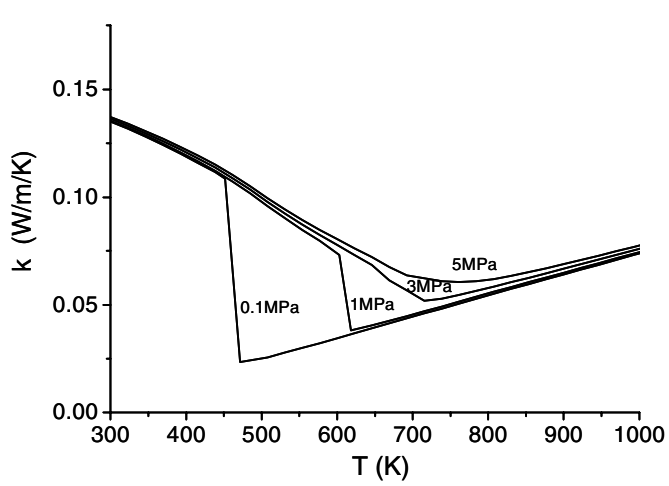

d)

Fig. 5 Computed thermodynamic and transport properties of the 10-component kerosene surrogate with temperature variation: a) densitytemperature isobars, b) specific heat-temperature isobars, c) dynamic viscosity-temperature isobars, and d) thermal conductivity-temperature isobars. 
Table 2 Summary of test conditions

\begin{tabular}{lccccc}
\hline \hline $\begin{array}{c}\text { Test } \\
\text { no. }\end{array}$ & $\begin{array}{c}\text { Pressure, } \\
\mathrm{MPa}\end{array}$ & $\begin{array}{c}\text { Fuel preheat temperature } \\
\text { at first-stage heater, K }\end{array}$ & $\begin{array}{c}\text { Initial temperature at } \\
\text { second-stage heater, K }\end{array}$ & $\begin{array}{c}\text { Measured mass } \\
\text { flow rate, g/s }\end{array}$ & $\begin{array}{c}\text { Maximum wall } \\
\text { heat flux, W/cm }\end{array}$ \\
\hline 1 & 2.7 & no & 770 & 15 & 5.5 \\
2 & 3.5 & no & 790 & 19 & 8 \\
3 & 4.2 & no & 770 & 24 & 6.5 \\
4 & 4.5 & no & 710 & 29 & 6.2 \\
5 & 3.0 & 460 & 750 & 26 & 4.5 \\
6 & 3.6 & 500 & 790 & 30 & 5 \\
7 & 4.6 & 460 & 735 & 32 & 6 \\
8 & 3.5 & no & 860 & 65 & 23 \\
9 & 4.0 & no & 750 & 80 & 80 \\
10 & 4.2 & no & 845 & & 26 \\
\hline \hline
\end{tabular}

reduction in viscosity near the critical temperature is noted, as shown in Fig. 5c.

\section{Results and Discussion}

\section{A. Test Conditions}

Table 2 lists the experimental conditions for test cases with and without fuel preheating in the first-stage heater. The first seven tests were conducted with the 1.6-mm-diam sonic nozzle at varying pressures, whereas the last three tests with larger mass flow rates used the 3.08-mm-diam sonic nozzle. As listed in Table 2, kerosene at the first-stage heater was prepared at supercritical pressures and the test section was heated to $710-860 \mathrm{~K}$ before each run.

\section{B. Test Results}

Figure $\underline{6}$ shows the distributions of wall and fuel temperatures along the tube at $t=11 \mathrm{~s}$ (cf. Figure 2 for the time sequence) for test 2 without fuel preheating. As a result of absorbing heat from the wall, the fuel temperature rose from $300 \mathrm{~K}$ at the inlet to $765 \mathrm{~K}$ near the outlet and, at $x \sim 11 \mathrm{~m}$, the bulk fuel temperature approached the wall temperature. Axial distributions of local wall heat flux $\left(q_{w}\right)$ at two reference times, $t=9$ and $12 \mathrm{~s}$, are plotted and compared in Fig. 7a. It is seen that the heat flux distributions at $t=9$ and $12 \mathrm{~s}$ are fairly close, indicating stable heat transfer characteristics for this time duration, consistent with the discussion of Fig. 2. In the region of $0 \leq x \leq 10 \mathrm{~m}, q_{w}$ varied from $\sim 3.5$ to $8 \mathrm{~W} / \mathrm{cm}^{2}$, with an average value of $5.6 \mathrm{~W} / \mathrm{cm}^{2}$. This is the region in which effective heat transfer existed and in which the experimental data were used for further analysis/correlation. Reynolds number distribution along the tube at $t=9 \mathrm{~s}$ is presented in Fig. 7b. It was found that $R e$ increased by more than 2 orders of magnitude, from 3000 at the inlet to 110,000 near the outlet, which was caused by the drastic reduction in fuel viscosity when approaching the critical temperature. Though not shown here, the Prandtl number also changed considerably, from approximately 18 at the inlet to less than 1 at the outlet. Because of the wide variations of fuel properties and key parameters (e.g., $R e$ and $P r$, a detailed numerical simulation of supercritical kerosene flow in a heated tube is challenging.

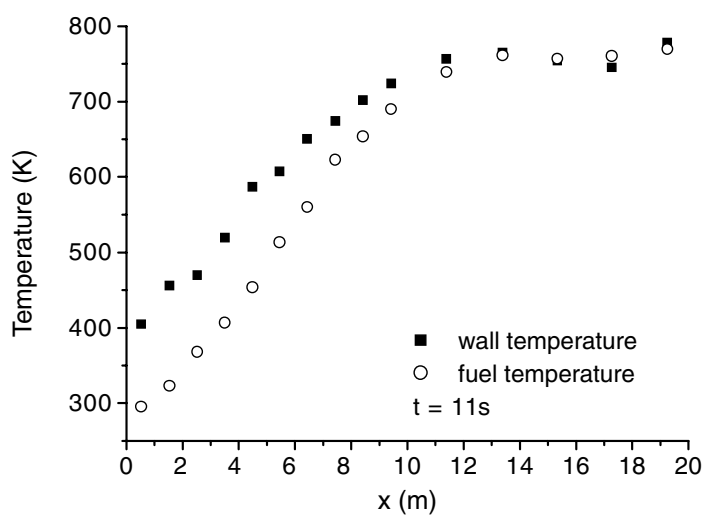

Fig. 6 Distributions of wall and fuel temperatures at $t=11 \mathrm{~s}$ for test 2 without fuel preheating.
The distributions of the Nusselt number at $t=9$ and $12 \mathrm{~s}$ are also shown and compared in Fig. 7c. Again, the distributions of the Nusselt number at two reference times are very close to each other, demonstrating stable heat transfer characteristics of the fuel flow.

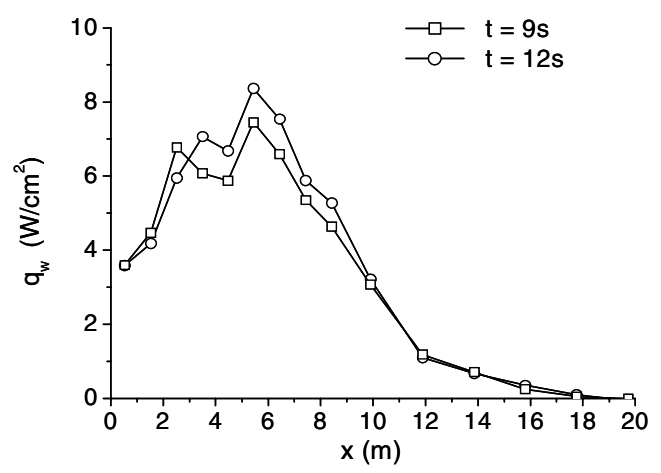

a)

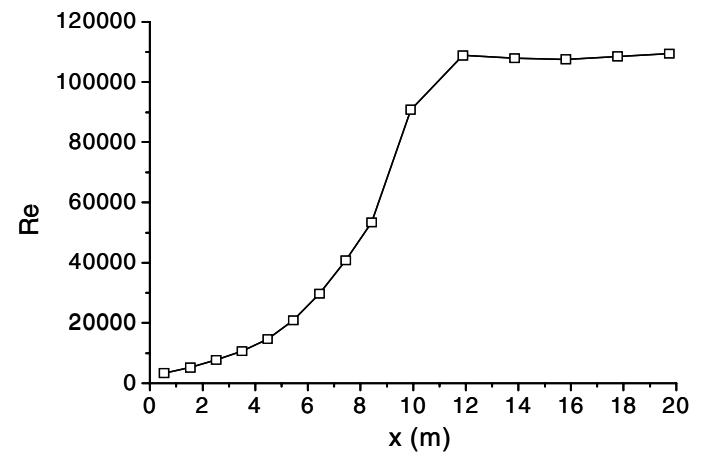

b)

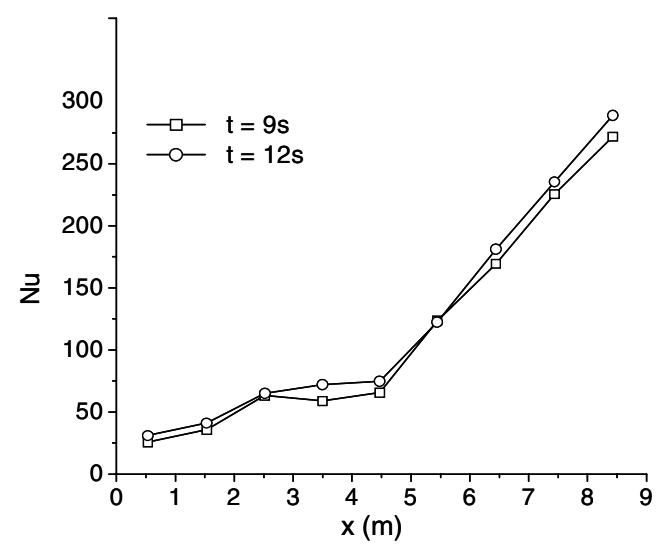

c)

Fig. 7 Axial distributions for test 2: a) heat flux, b) Reynolds number, and c) Nusselt number. 


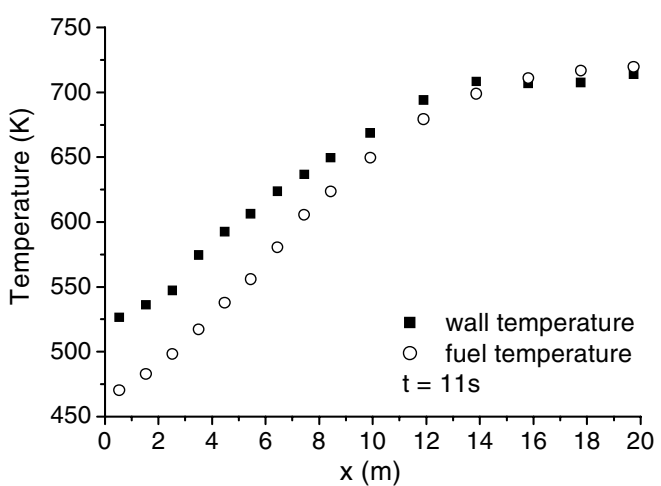

a)

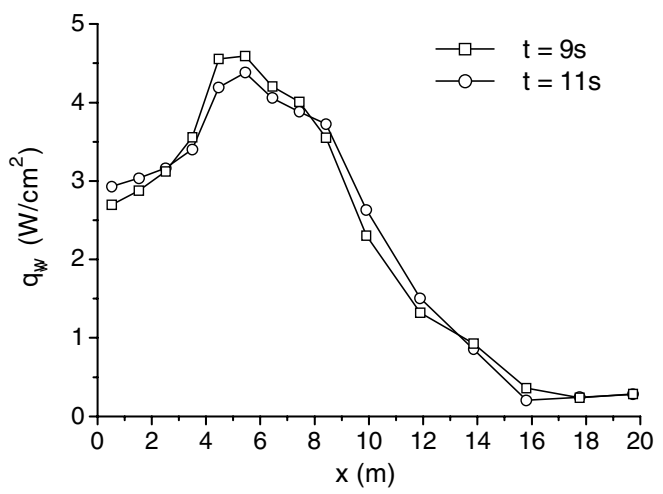

b)

Fig. 8 Test 5 with a fuel preheat temperature of $460 \mathrm{~K}$ : a) wall and fuel temperature distributions at $t=11 \mathrm{~s}$, and b) heat flux distributions at $t=9 \mathrm{~s}$ and $11 \mathrm{~s}$.

Although the Nusselt number is seen to generally increase along the tube, indicating an increase in the convective heat transfer, the axial variation of $\mathrm{Nu}$ was noted to be rather gentle in the plateau region of $2.5 \leq \times \leq 4.5 \mathrm{~m}$. This plateau region corresponds to a transition region beyond which substantial changes in fuel flow properties occur, which will be discussed in due course.

The measured wall and fuel temperature distributions along the tube at $t=11 \mathrm{~s}$ for test 5 with a fuel preheat temperature of $460 \mathrm{~K}$ are plotted in Fig. 8a, whereas the wall heat flux distributions at $t=9$ and $11 \mathrm{~s}$ are illustrated and compared in Fig. $8 \mathrm{~b}$. Similar to Fig. 6 , the fuel temperature distribution shows an increasing trend and, at $\bar{x} \sim 14 \mathrm{~m}$, the bulk fuel temperature approaches the wall temperature, leading to a substantial reduction in heat flux of less than $1 \mathrm{~W} / \mathrm{cm}^{2}$ beyond $x \sim 12 \mathrm{~m}$. The closeness of the heat flux distributions at $t=9$ and $11 \mathrm{~s}$ further indicates that the stable heat transfer characteristics were established.

\section{Heat Transfer Characteristics of Kerosene Flows}

Figure 9a plots $N u$ versus $R e$ in logarithmic coordinates for test 10 with a relatively large mass flow rate of $80 \mathrm{~g} / \mathrm{s}$. The Nusselt number is shown to increase with an increasing Reynolds number, indicating an increasing importance of the convective heat transfer of fuel flow. Furthermore, Fig. 9a illustrates distinct regions in terms of the $\mathrm{Nu}-\mathrm{Re}$ correlation. For $15,000 \leq \mathrm{Re} \leq 25,000$ (region 1), $\mathrm{Nu}$ increased with $R e$ with a power of approximately 0.85 , whereas for

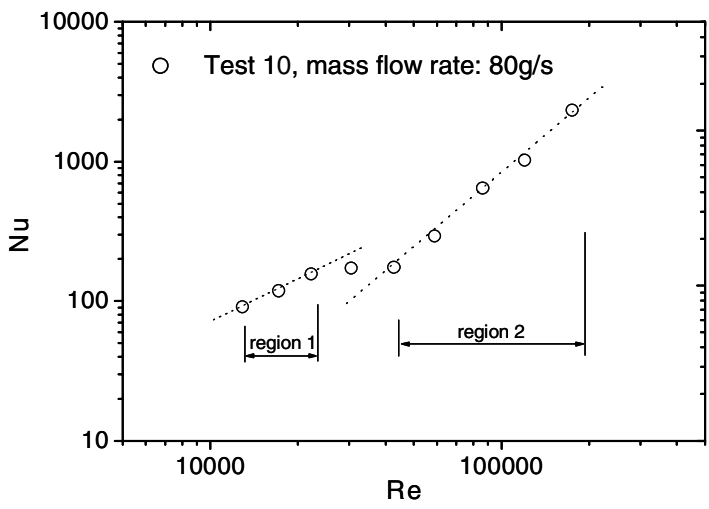

a)

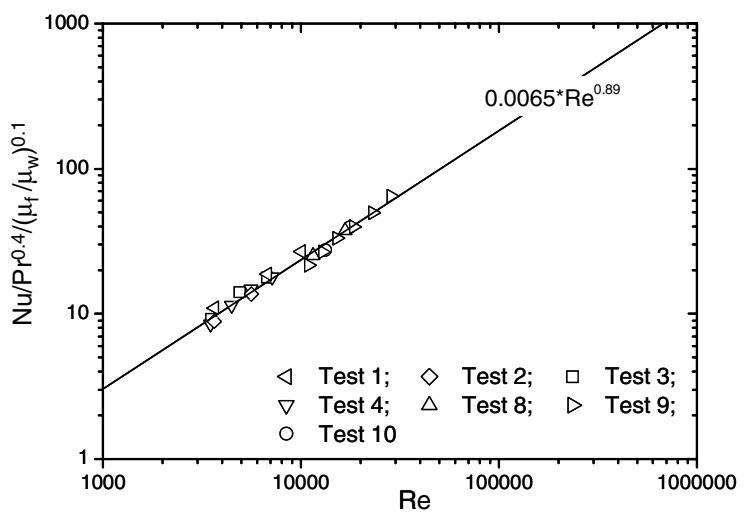

a)

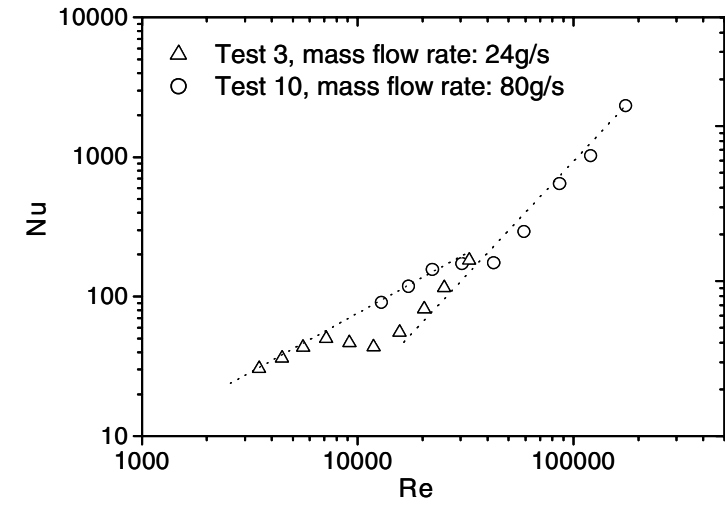

b)

Fig. 9 Nusselt number versus Reynolds number: a) test 10, and b) test 3 and 10.

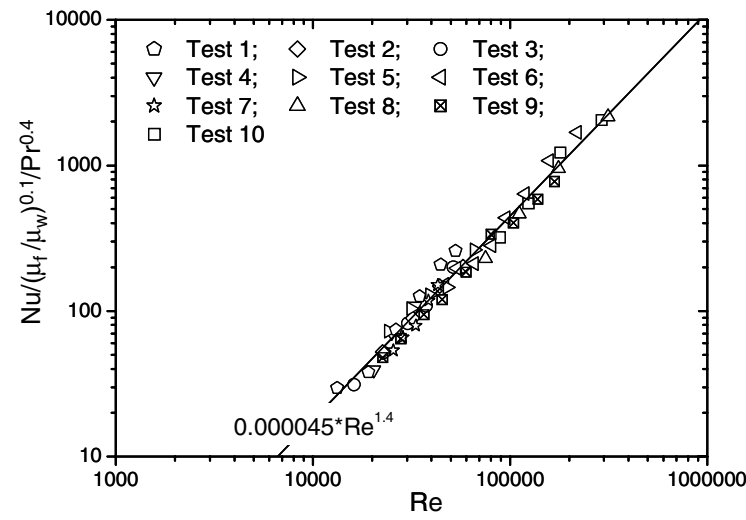

b)

Fig. 10 Heat transfer correlations based on the present experimental data: a) region 1, and b) region 2. 
Table 3 Comparison of heat transfer correlations for common kerosene-type fuels

\begin{tabular}{lcllll}
\hline \hline$N u=c \operatorname{Re}^{a} \operatorname{Pr}^{b}\left(\propto_{f} / \propto_{w}\right)^{d}$ & & $c$ & $a$ & $b$ & $d$ \\
\hline China no. 3 kerosene & Present study in region 1 & 0.0065 & 0.89 & 0.4 & 0.1 \\
JP-7 & {$[15]$} & 0.008 & 0.873 & 0.451 & 0 \\
JP-8 & {$[\underline{16}]$} & 0.01 & 0.906 & 0.4 & 0 \\
\hline \hline
\end{tabular}

$45,000 \leq R e \leq 200,000$ (region 2), the power index became approximately 1.35 . The transition from region 1 to 2 was noted to be in the range of $25,000 \leq R e \leq 45,000$ for this test case. Such a change in the power index was also found in other tests. Figure $9 \mathrm{~b}$ shows the results of test 3 with a mass flow rate of $24 \mathrm{~g} / \mathrm{s}$ and the comparison with test 10 . Similarly, the power indexes characterizing the increase of $N u$ with $R e$ for test 3 were 0.85 and 1.35 in regions 1 and 2, respectively. However, the transition region for test 3 corresponded to $7000 \leq R e \leq 15,000$.

It was further noted that the characteristic temperatures corresponding to the beginning of the transition region and the beginning of region 2 were the inner wall temperatures of $\sim 520$ and $\sim 600 \mathrm{~K}$, respectively. These results suggest that, at a supercritical pressure, when kerosene in the vicinity of the wall was heated to a temperature of approximately $520 \mathrm{~K}$, it would be no longer at a pure compressed liquid state; consequently, the changes in fuel properties affected the heat transfer of the fuel flow. Additionally, when the fuel near the wall was heated to above $600 \mathrm{~K}$, the fuel became supercritical and heat convection was significantly enhanced. Enhancement in the convective heat transfer of kerosene flow when approaching its critical temperature has been observed in many of other studies $[9,15,25]$ under much larger wall heat fluxes $\left(500-1000 \mathrm{~W} / \mathrm{cm}^{2}\right)$. However, it has to be pointed out that, for the current study with lower heat fluxes, neither a sudden change in heat convection, nor pressure oscillation and the associated flow instability, were observed, as found in the literature $[9,15,25]$. Instead, a relatively smooth transition region exists before entering region 2 .

\section{Heat Transfer Correlations}

The heat transfer data in regions 1 and 2 were further correlated with the fuel flow properties. Data in region 1 were correlated based on the expression of $N u=c \operatorname{Re}^{a} \operatorname{Pr}^{b}\left(\propto_{f} / \propto_{w}\right)^{d}$, which has been used in many previous studies [8,13-17]. In this expression, the power in the Reynolds number represents the effect of the flowfield on heat convection, whereas the power in the Prandtl number denotes the effect of fuel properties. In addition, this expression takes into account the change in viscosity due to the temperature difference between the bulk fuel flow temperature and the heat transfer surface temperature.

The heat transfer data in region 1 were found to correlate well for the coefficients of $c=0.0065, a=0.89, b=0.4$, and $d=0.1$. Figure 10 a shows such a correlation by plotting $\mathrm{Nu} /\left[\mathrm{Pr}^{0.4}\left(\propto_{f} /\right.\right.$ $\left.\left.\propto_{w}\right)^{0.1}\right]$ versus $R e$, with a standard deviation between the experimental data and the correlation of $3.6 \%$. Table 3 lists and compares the current correlation and the literature data $[15,16]$ at fuel temperatures of $\leq 500 \mathrm{~K}$ for various kerosene-type fuels. As shown in Table 3, China no. 3 kerosene has relatively lower heat convection capability as compared with JP-8 and JP-7. Moreover, the current heat transfer correlation for kerosene is close to that of [15], even though the wall heat fluxes were quite different in the two studies. It was found that in all these correlations the Reynolds number effect is dominant, whereas the Prandtl number effect is less important and the dependence on Prandtl number can be specified as $\mathrm{Pr}^{0.4}$.

When entering region 2 , the fuel near the wall became supercritical; hence, the convective heat transfer was significantly enhanced. The heat transfer data correlation in region 2 based on $N u=c \operatorname{Re}^{a} \operatorname{Pr}^{b}\left(\propto_{f} / \propto_{w}\right)^{d}$ yielded $c=0.000045, a=1.4$, $b=0.4$, and $d=0.1$, with a standard derivation of $6.8 \%$, as shown in Fig. 10b. As expected, the correlation of region 2 leads to a larger power index for the Reynolds number than that of region 1, indicating a more important Reynolds number dependency. This can be explained by the significant changes in fuel properties when transitioning from region 1 to 2 . At low temperatures, the fuel is at a compressed liquid state. Thus, the power index for the Reynolds number effect is close to the typical value for many common liquid fuels, which is approximately 0.8 . Because the properties of supercritical fuels present some unique features, as addressed earlier, the corresponding heat transfer characteristics are affected, as reflected by the increase in the power index associated with the Reynolds number.

\section{Conclusions}

A series of heat transfer characterization experiments using China no. 3 kerosene flows in a heated tube system were conducted under supercritical pressure conditions. Both the bulk fuel flow temperature and the tube wall temperature along the flow direction were measured simultaneously. Based on the measured fuel and wall temperature distributions along the flowpath and the calculated fuel properties using a 10-component kerosene surrogate, the local heat flux distribution was deduced through a heat transfer analysis. The following is a list of several conclusions drawn from this investigation.

1) The current heating system can accommodate a wide range of pressures, temperatures, mass flow rates, and Reynolds numbers (cf. Table 2) for kerosene experimentation.

2) Under supercritical pressures, when the kerosene temperature along the flowpath was increased toward and beyond the critical temperature, significant changes in fuel/flow properties, such as density (cf. Figure 5a) and Reynolds number (cf. Figure 7b), were noticed.

3) Based on the results of the heat transfer analysis, the heat transfer characteristics of kerosene flows can be classified as three regions (cf. Figure 9): a compressed liquid region (region 1), a supercritical fuel region (region 2), and a transition region that bridges regions 1 and 2 . Convective heat transfer was greatly enhanced in region 2 when the fuel temperature near wall exceeded $600 \mathrm{~K}$.

4) The correlation of the heat transfer data in region 1 yielded a result similar to that for other kerosene-type fuels at temperatures of less than $500 \mathrm{~K}$, whereas the heat convection capability of the present China no. 3 kerosene was found to be lower than JP-7 and JP-8 (cf. Table 3 ).

5) The correlation for the heat transfer data in region 2 shows an increased Reynolds number dependency (cf. Figure 10). Such a change in heat convection characteristics is expected to be caused by the transition of the fuel state from the compressed liquid state to the supercritical state with increasing temperature.

The current study focused on the supercritical heat transfer without fuel thermal cracking. As the fuel temperature is further increased $(\geq 800 \mathrm{~K})$, kerosene will undergo an endothermic decomposition process, which provides additional heat sink capacity. To cover the entire range of the fuel temperature variations for scramjet applications, a follow-up investigation is currently underway to upgrade the existing heating system and experimentally study the heat transfer characteristics of kerosene flows under mild-tomoderate thermal cracking conditions.

\section{Acknowledgments}

This work is funded by the Natural Science Foundation of China under contract 10672169 and 10742003 . The authors would like to thank Xinian Lu, Ying Li, Xuesong Wei, Chenxi Jiang, and Peng Huang, for their technical support. 


\section{References}

[1] Lander, H., and Nixon, A. C., "Endothermic Fuels for Hypersonic Vehicles," Journal of Aircraft, Vol. 8, No. 4, 1971, pp. 200-207. doi: $10.2514 / 3.44255$

[2] Wagner, W. R., and Shoji, J. M., "Advanced Regenerative Cooling Techniques for Future Space Transportation Systems," AIAA Paper 75$1247,1975$.

[3] Huang, H., Spadaccini, L. J., and Sobel, D. R., "Fuel-Cooled Thermal Management for Advanced Aero-Engines," Journal of Engineering for Gas Turbines and Power, Vol. 126, 2004, pp. 284-293. doi:10.1115/1.1689361

[4] Sobel, D. R., and Spadaccini, L. J., "Hydrocarbon Fuel Cooling Technologies for Advanced Propulsion," Journal of Engineering for Gas Turbines and Power, Vol. 119, 1997, pp. 344-351. doi:10.1115/1.2815581

[5] Fan, X-J., Yu, G., Li, J-G., Lu, X-N., Zhang, X-Y., and Sung, C. J., "Combustion and Ignition of Thermally Cracked Kerosene in Supersonic Model Combustors," Journal of Propulsion and Power, Vol. 23, No. 2, 2007, pp. 317-324. doi: $10.2514 / 1.26402$

[6] Yang, V., "Modeling of Supercritical Vaporization, Mixing and Combustion Processes in Liquid-Fueled Propulsion System," Proceedings of the Combustion Institute, Vol. 28, 2000, pp. 925-942.

[7] Edwards, T., and Maurice, L. Q., "Surrogate Mixtures to Represent Complex Aviation and Rocket Fuels," Journal of Propulsion and Power, Vol. 17, 2001, pp. 461-466. doi: $10.2514 / 2.5765$

[8] Hendricks, R. C., Simoneau, R. J., and Smith, R. V., "Survey of Heat Transfer to Neat Critical Fluids," NASA TN D-5886, 1970.

[9] Hitch, B., and Karpuk, M., "Experimental Investigation of Heat Transfer and Flow Instabilities in Supercritical Fuels," AIAA Paper 973043, 1997.

[10] Sieder, E. N., and Tate, C. E., "Heat Transfer and Pressure Drop of Liquids in Tubes," Industrial and Engineering Chemistry, Vol. 28, 1936, pp. 1429-1435. doi:10.1021/ie50324a027

[11] Dziedzic, W. M., Jones, S. C., Gould, D. C., and Petley, D. H., "Analytical Comparison of Convective Heat Transfer Correlations in Supercritical Hydrogen," Journal of Thermophysics and Heat Transfer, Vol. 7, No. 1, 1993, pp. 68-73. doi: $10.2514 / 3.11571$

[12] Lee, S. H., and Howell, J. R., "Laminar Forced Convection at Zero Gravity to Water near the Critical Region," Journal of Thermophysics and Heat Transfer, Vol. 10, No. 3, 1996, pp. 504-510. doi: $10.2514 / 3.817$
[13] Giovanetti, A. J., Spadaccini, L. J., and Szetela, E. J., "Deposit Formation and Heat Transfer Characteristics of Hydrocarbon Rocket Fuels," Journal of Spacecraft and Rockets, Vol. 22, No. 5, 1985, pp. $574-580$. doi: $10.2514 / 3.25067$

[14] Meyer, M. L., "Electrically Heated Tube Investigation of Cooling Channel Geometry Effects," AIAA Paper 95-2500, 1995.

[15] Hu, Z-H., Chen, T-K., Luo, Y.-S., Zheng, J.-X., and Tang, M., "Heat Transfer Characteristics of Kerosene at Supercritical Pressure," Journal of Xian Jiaotong University, Vol. 33, No. 9, 1999, pp. 116120.

[16] Stiegemeier, B., Meyer, M. L., and Taghavi, R., "A Thermal Stability and Heat Transfer Investigation of Five Hydrocarbon Fuels," AIAA Paper 02-3873, 2002.

[17] Bates, R. W., and Edwards, T., "Heat Transfer and Deposition Behavior of Hydrocarbon Rocket Fuels," AIAA Paper 03-0123, 2003.

[18] Heiser, W. H., and Pratt, D. T., Hypersonic Airbreathing Propulsion, AIAA, Washington, D.C., 1994, pp. 485-490.

[19] Fan, X-J., Yu, G., and Li, J-G., "Flow Rate Analysis and Calibrations of Kerosene Cracking for Supersonic Combustion," AIAA Paper 05-3555, 2005.

[20] Fan, X-J., Yu, G., Li, J-G., Zhang, X-Y., and Sung, C. J., "Investigation of Vaporized Kerosene Injection and Combustion in a Supersonic Model Combustor," Journal of Propulsion and Power, Vol. 22, No. 1, 2006, pp. 103-110. doi: $10.2514 / 1.15427$

[21] Fan, X-J., Yu, G., Li, J-G., Zhang, X-Y., Yue, L.-J., and Sung, C. J., "Effects of Entry Conditions on Cracked Kerosene-Fueled Supersonic Combustor Performance," Combustion Science and Technology, Vol. 179, No. 10, 2007, pp. 2199-2217. doi: $10.1080 / 00102200701386198$

[22] Ely, J. F., and Huber, M. L., NIST Standard Reference Database 4-NIST Thermophysical Properties of Hydrocarbon Mixtures, National Inst. of Standards, Gaithersburg, MD, Feb. 1990.

[23] Fisher, G. D., and Leland, T. W., "The Corresponding States Principle Using Shape Factors," Industrial and Engineering Chemistry Fundamentals, Vol. 9, 1970, pp. 537-544. doi:10.1021/i160036a003

[24] Sun, Q-M., Mi, Z-T., and Zhang, X-W., "Determination of Critical Properties $\left(T_{c}, P_{c}\right)$ of Endothermic Hydrocarbon Fuels RP-3 and Simulated JP-7," Journal of Fuel Chemistry and Technology, Vol. 34, No. 4, 2006, pp. 466-470.

[25] Linne, D. L., and Meyer, M. L., "Evaluation of Heat Transfer and Thermal Stability of Supercritical JP-7 Fuel," AIAA Paper 97-3041, 1997. 